\title{
Intraday Index Volatility: Evidence From Currency Adjusted Stock Indices
}

\author{
Terrance Jalbert, University of Hawaii Hilo, USA
}

\begin{abstract}
A recent research stream develops currency adjusted stock indices. The analysis in previous papers is limited to daily closing data. This paper extends the existing body of literature by examining tick data. We examine tick data from 2002 through 2013 for eight indices. In general, results show the Dollar Index adjusted indices display significantly lower variation than the unadjusted indices. Correlation between the Dollar Index and unadjusted stock indices is negative. Both raw and Dollar index adjusted indices display departures from intra-tick symmetry. The results also show that Dollar Index changes explain as much as fifteen percent of wealth changes.
\end{abstract}

Keywords: Stock Index; Dollar Index; Currency Value

\section{INTRODUCTION}

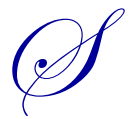

tandard stock indices are based on the domestic currency. Fluctuation in the underlying currency value distorts purchasing power changes implied by index level changes. Currency adjusted indices capture wealth changes resulting from both stock value changes and currency value changes. As such, currency adjusted indices provide a better measure of wealth changes. A recent article by Jalbert (2012) develops the first known currency adjusted stock indices. He develops indices using U.S. stock indexes as adjusted using the Major and Broad currency value measures available from the U.S. Federal Reserve. He uses close of day index and currency data to develop his currency-adjusted indices. This approach suffers from several limitations as noted in Jalbert (2014). A critical limitation of these indices is that Major and Broad currency value data are only available for close of day values. The lack of intraday data limits the usefulness of these indices for individuals interested in more frequent index valuations.

In a later paper, Jalbert (2014) uses Dollar Index (DXY) data as an alternative to Major and Broad currency values. Dollar Index data has the advantage of intraday quotations, futures contract availability and is available in exchange traded and mutual funds. Moreover, the Dollar Index is widely reported in news outlets. The Dollar Index was initiated in 1973 with a value of 100 . Higher index values indicate a stronger dollar value.

This paper extends the work of Jalbert (2012) and Jalbert (2014). Like Jalbert (2014), this paper uses the Dollar Index for computing currency adjusted indices. Jalbert (2014) limited his analysis to close of day index values. This paper extends the literature by examining intraday data. The remainder of the paper is organized as follows. The following two sections provide a review of the relevant literature and discussion of the data and methodology used in the paper. Next, the test results are presented. The paper closes with some concluding comments and suggestions for future research.

\section{LITERATURE REVIEW}

A large body of literature addresses stock indices. However, only two known papers examine currency value adjusted indices. Thus we relate this study to general literature on stock indices. We examine three lines of literature, the relationship between stock indices and stock index futures, stock index volatility, and stock price reactions to stock index component changes. 
One line of literature examines the extent to which cycles occur in stock index levels, returns and volatility. If predicable cycles exist, the market does not conform to weak form market efficiency. Alvarez-Ramirez and Rodriguez (2011) examine the Dow Jones Industrial Average (DJIA) for cyclical patterns. They find cycles appear with frequencies between 4.5 and 22 years. Wong, Lian and Cheong (2009) find the DJIA has volatility cycles with index changes following a Gaussian process. Opong, Mulholland, Fox and Farahmand (1999) find the London Financial Times Stock Exchange, All Share Index has cycles that occur more often than expected under a random series.

Lakonishok and Smidt (1998) examine DJIA seasonality patterns. Over a ninety-year period, they find persistent turn of the week, month, and year patterns along with holiday return anomalies. Donaldson and Kim (1993) find support and resistance levels around DJIA multiples of 100. They identify disproportionate moves when an index breaks a 100 multiple barrier. Recent research uses neural networks and hybrid models in an attempt to predict stock index levels (Ferreira, Vasconcelos and Adeodato, 2008).

Breen, Glosten and Jagannathan (1989) forecast stock index excess returns. Their evidence shows onemonth interest rates forecast the sign and variance of stock index excess returns. Martens, van Dijk and de Potter (2009) find incorporating macroeconomic effects into their prediction model improved out-of-sample forecast accuracy for twenty-day-ahead S\&P 500 Index volatility forecasts.

If incorrectly priced, index options and futures produce arbitrage opportunities. Taylor (2007) examines mispricing associated with futures and spot price differences. He finds S\&P 500 arbitrageurs prefer middle-of-theday trades. Hora and Jalbert (2006) examine distribution characteristics of the DJIA over a 100-year period. Based on index distribution properties identified, they propose a Black and Scholes option-pricing model derivation based on the Student t-distribution (Black and Scholes, 1973). Empirical results show the adjusted options valuation more accurately prices Down Jones Industrial Average index options than the Black and Scholes model.

A large body of literature examines stock index volatility. French and Roll (1986) find higher volatility when stock exchanges are open. Several articles relate volatility changes to macroeconomic variables including time varying volatility and financial leverage (Christie, 1982), expected stock return changes (Merton, 1980 and Bollerslev, Engle and Wooldridge 1988) and interest rates (Lauterbach, 1989).

Periodically, stock index components change. Mergers, bankruptcy and other corporate events necessitate these changes. Several authors examine the impacts of index additions and deletions. Findings show stock price increases for firms added to an index. Similarly, stock prices of firms deleted from an index decline (Shleifer, 1986, Beneish and Gardner, 1995). Some attribute index addition induced stock price increases to improved investor awareness and reduced price volatility (Liu 2011). Chen, Noronha and Singal (2006) find arbitrage activity around index changes exists. Their examination shows index change arbitrage results in a collective loss approaching $\$ 2.1$ billion annually for index fund investors. Jankovskis (2002) finds a 1.2 percent annual downward bias in Russell 2000 Index returns due to rebalancing.

As noted earlier Jalbert (2012) first introduced currency value adjusted stock indices. He computes currency adjusted indices based on existing U.S. stock indices. His statistical analysis shows significant differences in unadjusted and adjusted index levels as well as daily and annual index returns. Unadjusted and adjusted index annual returns for the Dow Jones Industrial Average differ by as much as 18.211 percent. A comparison of return signs show differences on 12.99 percent of all trading days. Thus, the unadjusted index indicates a positive (negative) return, but the adjusted index indicates a negative (positive) return. He finds adjusted and unadjusted indices have different distribution properties. Regression results show currency value changes explain as much as 8.44 percent of total wealth changes.

Jalbert (2014) provides an extension of Jalbert (2012) by using a different dollar value measure. Jalbert (2014), provides similar results with one notable exception. Jalbert (2014) finds the currency value changes explain a larger portion of the adjusted index changes. The results indicate that currency value changes explain as much as 15 percent of adjusted index changes. 


\section{DATA AND METHODOLOGY}

Data for each trading minute for eight U.S. Stock Indices and the U.S. Dollar Index were obtained from Pi Trading (Pi Trading, 2013). Pi Trading provides open, high, low and close information for each trading minute throughout the day. The data extends from August 5, 2001 through April 5, 2013. Index data were matched with Dollar Index data for each trading tick. The Dollar Index equals the value of a basket of six currencies used to estimate the U.S. dollar value. As noted earlier, the index started in March of 1973 with value of 100. Higher index levels imply a stronger dollar. Lower index levels imply a weaker dollar. Dollar Index values show considerable variation, ranging from 164.72 in February 1985 to 70.698 in March 2008. Some authors criticize the index because of the currencies used to develop the index and currency weightings (Koch, 2013). Despite these limitations, the index is widely quoted.

This paper analyzes Seven Stock Indices: The Dow Jones Industrial Average (DJIA), NASDAQ Composite (COMPX), NASDAQ 100 (NDX), S\&P 500 (SPX), S\&P 400 (MID), Russell 3000 (RUA), and Russell 1000 (RUI). The Philadelphia Housing Index (HGX) provides an index of real estate values. The indices examined were selected because they are widely reported and the availability of data for analysis.

Table 1, Panel A shows summary statistics of the data. For each index, as many as 65,006 stock and real estate index observations could not be matched with Dollar Index data. This occurred primarily due to different trading hours for the Dollar Index and Stock Exchanges. Data prior to December 31, 2001 were eliminated from the data to create full data years for analysis. The final dataset extends from December 31, 2001 through April 5, 2013. The datasets include as many as 1,036,037 observations for each index.

Table 1: Summary Statistics

\begin{tabular}{|c|c|c|c|c|c|c|c|c|}
\hline Index & Symbol & $\begin{array}{l}\text { Total } \\
\text { Obs. }\end{array}$ & $\begin{array}{c}\text { Eliminated } \\
\text { Obs. }\end{array}$ & $\begin{array}{c}\text { Observations } \\
\text { Examined }\end{array}$ & High & Low & Mean & Std. Dev. \\
\hline \multicolumn{9}{|c|}{ Panel A: Raw Indices } \\
\hline Dow Jones Ind. & INDU & $1,100,603$ & 64,743 & $1,035,860$ & $14,683.80$ & $6,470.91$ & $10,937.73$ & $1,668.62$ \\
\hline NASDAQ Comp. & COMPX & $1,100,793$ & 64,810 & $1,035,983$ & $3,270.09$ & $1,108.73$ & $2,222.78$ & 483.82 \\
\hline NASDAQ 100 & NDX & $1,101,073$ & 65,006 & $1,036,067$ & $2,878.02$ & 795.25 & $1,771.91$ & 482.30 \\
\hline S\&P 500 & SPX & $1,099,725$ & 64,683 & $1,035,042$ & $1,576.03$ & 666.79 & $1,191.69$ & 192.10 \\
\hline S \& P 400 & MID & $1,097,033$ & 64,365 & $1,032,668$ & $1,154.56$ & 370.90 & 729.34 & 179.91 \\
\hline Phil. Housing & HGX & $1,046,733$ & 61,386 & 985,347 & 293.58 & 54.33 & 152.11 & 56.58 \\
\hline Russell 3000 RUA & RUA & $1,099,728$ & 64,891 & $1,034,837$ & 936.53 & 384.41 & 691.22 & 119.53 \\
\hline Russell 1000 RUI & RUI & $1,099,215$ & 64,775 & $1,034,440$ & 873.76 & 362.27 & 648.78 & 109.94 \\
\hline Dollar Index & DXY & & & & 120.37 & 71.15 & 85.51 & 10.11 \\
\hline \multicolumn{9}{|c|}{ Panel B: Dollar Index Adjust Indices } \\
\hline Dow Jones Ind. & INDU & & & & $12,622.7$ & $5,730.42$ & $9,262.05$ & 1198.66 \\
\hline NASDAQ Comp. & COMPX & & & & $2,712.87$ & $1,122.97$ & $1,869.14$ & 319.15 \\
\hline NASDAQ 100 & NDX & & & & $2,344.24$ & 857.52 & $1,484.75$ & 329.18 \\
\hline S\&P 500 & SPX & & & & $1,381.31$ & 590.19 & $1,009.69$ & 144.46 \\
\hline S \& P 400 & MID & & & & 957.82 & 352.32 & 610.97 & 117.18 \\
\hline Phil. Housing & HGX & & & & 262.32 & 48.22 & 128.71 & 51.35 \\
\hline Russell 3000 RUA & RUA & & & & 776.56 & 340.25 & 584.42 & 84.63 \\
\hline Russell 1000 RUI & RUI & & & & 730.32 & 320.65 & 548.82 & 79.01 \\
\hline Index & Symbol & Skewness & Kurtosis & & & & & \\
\hline \multicolumn{9}{|c|}{ Panel A: Raw Indices } \\
\hline Dow Jones Ind. & INDU & -0.0616 & -0.7379 & & & & & \\
\hline NASDAQ Comp. & COMPX & -0.0577 & -0.6140 & & & & & \\
\hline NASDAQ 100 & NDX & 0.4001 & -0.5346 & & & & & \\
\hline S\&P 500 & SPX & -0.2103 & -0.6848 & & & & & \\
\hline S \& P 400 & MID & -0.0399 & -0.9309 & & & & & \\
\hline Phil. Housing & HGX & 0.6133 & -0.8005 & & & & & \\
\hline Russell 3000 RUA & RUA & -0.2105 & -0.8108 & & & & & \\
\hline Russell 1000 RUI & RUI & -0.1959 & -0.7798 & & & & & \\
\hline Dollar Index & DXY & 1.4710 & 1.9848 & & & & & \\
\hline
\end{tabular}


(Table 1 continued)

\begin{tabular}{|c|c|c|c|}
\hline \multicolumn{4}{|c|}{ Panel B: Dollar Index Adjusted Indices } \\
\hline Dow Jones Ind. & INDU & 0.0171 & 0.0781 \\
\hline NASDAQ Comp. & COMPX & 0.1238 & -0.3639 \\
\hline NASDAQ 100 & NDX & 0.6788 & -0.0866 \\
\hline S\&P 500 & SPX & -0.0299 & -0.1693 \\
\hline S \& P 400 & MID & 0.1524 & -0.5495 \\
\hline Phil. Housing & HGX & 0.6340 & -0.6751 \\
\hline Russell 3000 RUA & RUA & -0.1099 & -0.4486 \\
\hline Russell 1000 RUI & RUI & -0.0855 & -0.3684 \\
\hline \multicolumn{4}{|c|}{$\begin{array}{l}\text { This table shows summary statistics for the data sample. The column labeled Total Obs. indicates the number of tick observations from } \\
\text { August } 8,2001 \text { through April } 5,2013 \text {. The column labeled Eliminated Obs. were those observations where stock index data were available, } \\
\text { but Dollar Index data were not available. These observations were eliminated from further consideration. The column labeled Observations } \\
\text { Examined indicates the number of observations used for analysis in the remainder of the paper. The columns labeled High, Low and Mean } \\
\text { indicated the maximum, minimum and average index level over the time period examined. Panel A shows results for the raw series and the } \\
\text { dollar index. Panel B shows results for the dollar adjusted series. }\end{array}$} \\
\hline
\end{tabular}

The column labeled Total Observations indicates the number of tick observations from August 8, 2001 through April 5, 2013. The column labeled Eliminated Obs. were those observations where stock index data were available, but Dollar Index data were not available. These observations were eliminated from further consideration. The column labeled Observations Examined indicates the number of observations that were included for analysis in the remainder of the paper. The columns labeled High, Low and Mean indicated the maximum, minimum and average index level over the time period examined.

Consider an index with level, $R I_{t}$ at time t. Consider further a dollar value index with base level of 100 and current level, $D I_{t}$, at time $t$. Then a dollar index adjusted index, $A I_{t}$, at time $t$ equals:

$A I_{t}=\frac{R I_{t}}{D I_{t}} * 100$

To demonstrate the use of Equation 1, suppose a raw stock index level equals 1,000. The corresponding dollar index level equals 115 . Then the adjusted index equals:

$A I_{t}=\frac{1,000}{115} * 100=1,150$

The adjusted index equals the raw index when the dollar index equals 100. The adjusted index exceeds the raw index when the dollar index exceeds 100 . The adjusted index is lower than the raw index when the dollar index is less than 100. We calculate Equation 1 for open, high, low and closing values for each data tick observation. These values provide the basis for this research. Table 1, Panel B shows summary statistics of the adjusted closing index levels. In each case, the raw series standard deviation exceeds the adjusted series standard deviation. This finding indicates currency value changes offset variation in the raw index series.

\section{RESULTS}

Next, we examine correlation between the raw and adjusted series. Table 2 shows the Pearson correlation statistics. With the exception of the Philadelphia Housing Index, the results show negative correlation between each adjusted indexes and the Dollar Index. Correlation ranges between 0.1818 for the Philadelphia Housing Index and 0.6882 for the Standard and Poor's 400 Index. Correlation between the raw and adjusted indexes ranges from 0.7073 for the Dow Jones Industrial Average and 0.9831 for the NASDAQ 100. These negative correlation results suggest movement in the Dollar Index offset changes in the raw index. This variance in the adjusted index relative to the raw index. 
Table 2: Correlation Analysis

\begin{tabular}{lccc}
\hline Index & Symbol & Dollar Index & Raw and Adjusted Series \\
\hline Dow Jones Industrial & INDU & -0.5423 & 0.7037 \\
NASDAQ Composite & COMPX & -0.6488 & 0.8912 \\
NASDAQ 100 & NDX & -0.6268 & 0.9831 \\
S\&P 500 & SPX & -0.4964 & 0.7430 \\
S \& P 400 & MID & -0.6882 & 0.9327 \\
Philadelphia Housing & HGX & 0.1818 & 0.9809 \\
Russell 3000 RUA & RUA & -0.5517 & 0.7837 \\
Russell 1000 RUI & RUI & -0.5367 & 0.7712 \\
\hline
\end{tabular}

This table shows correlation coefficients between the raw index, the Dollar Index and the adjusted series levels. The column labeled dollar index shows the correlation between the dollar index and the currency adjusted index. The column labeled Raw and Adjusted Series shows correlation levels between the unadjusted and dollar index adjusted indexes.

We continue with an examination of differences between the high, $H_{t}$, and low, $L_{t}$, index values for each trading tick. We compute the spread between high and low index levels, $S H L_{t}$, for each tick as follows:

$S H L_{t}=H_{t}-L_{t}$

Table 3 shows the spread analysis results. The set of columns, titled Raw Spread, show statistics for the high and low value spread at each trading tick for the raw index. The second set of columns, titled Adj. Spread, shows statistics for high and low value spread at each tick for the Dollar Index adjusted index. The third set of columns shows differences between the raw and adjusted spreads. The t-test for mean differences, conducted assuming unequal variance, compares the Dollar Index adjusted and Raw Index spreads. The results show significant mean spread differences for each series. With the exception of the Philadelphia housing index, mean raw index spreads significantly exceed adjusted index spreads. This suggests that dollar index adjusting the indices decreases intra-tick spread variation. The F-test formally examines the variance differences of the two spreads. The results indicate significantly different spread variations.

Next, we compare the open, high, low and closing index levels for each tick. For each observation we compute four intra tick spreads. Consider a tick observation with opening value, $O_{t}$, closing value, $C_{t}$, and high and low values as previously defined. Equation 3 shows the Open-High spread, $S O H_{t}$, calculations. Equation 4, 5 and 6 show the Open-Low, $S O L_{t}$, Close-High, $S C H_{t}$, and Close-Low, $S C L_{t}$ calculations respectively.

$$
\begin{aligned}
& S O H_{t}=O_{t}-H_{t} \\
& S O L_{t}=O_{t}-L_{t} \\
& S C H_{t}=C_{t}-H_{t} \\
& S C L_{t}=C_{t}-L_{t}
\end{aligned}
$$


Table 3: Intra Tick Spread Analysis

\begin{tabular}{|c|c|c|c|c|c|c|c|c|}
\hline \multirow[b]{2}{*}{ Index } & \multicolumn{2}{|c|}{ Raw Spread } & \multicolumn{2}{|c|}{ Adj. Spread } & \multicolumn{2}{|c|}{ Spread Difference } & \multirow[t]{2}{*}{$\begin{array}{c}\text { T-test for Mean } \\
\text { Difference }\end{array}$} & \multirow[t]{2}{*}{$\begin{array}{c}\begin{array}{c}\text { F-Test for Variance } \\
\text { Difference }\end{array} \\
\end{array}$} \\
\hline & Mean & Std. Dev. & Mean & Std. Dev. & Mean & Std. Dev. & & \\
\hline Dow Jones Ind & 4.6001 & 5.0227 & 3.8858 & 4.1906 & -0.7143 & 1.0883 & $-44.64 * * *$ & $1.465 * * *$ \\
\hline $\begin{array}{l}\text { NASDAQ } \\
\text { Comp }\end{array}$ & 0.7216 & 0.7329 & 0.6081 & 0.6060 & -0.1136 & 0.1655 & $-948.8 * * *$ & $1.463 * * *$ \\
\hline NASDAQ 100 & 0.7735 & 0.7498 & 0.6534 & 0.6286 & -0.1201 & 0.1711 & $-915.4 * * *$ & $1.423 * * *$ \\
\hline S\&P 500 & 0.3437 & 0.4217 & 0.2889 & 0.3465 & -0.0548 & 0.0904 & $-1,762 * * *$ & $1.481 * * *$ \\
\hline S\&P 400 & 0.1657 & 0.2484 & 0.1359 & 0.6131 & -0.0298 & 0.5821 & $-1,490 * * *$ & $0.1642 * * *$ \\
\hline Phil. Housing & 0.0877 & 0.0937 & 0.0724 & 0.0761 & -0.0153 & 0.0194 & $1.645^{* * *}$ & $1.516 * * *$ \\
\hline Russell 3000 & 0.1830 & 0.2203 & 0.1533 & 0.1801 & -0.0297 & 0.0478 & $-3,468 * * *$ & $1.497 * * *$ \\
\hline Russell 1000 & 0.1794 & 0.2121 & 0.1506 & 0.1738 & -0.0289 & 0.0460 & $-3,603 * * *$ & $1.489 * * *$ \\
\hline
\end{tabular}

This table shows an analysis of index tick data. The set of column titled Raw Spread shows statistics for the raw index difference between the high and low values at each trading tick. The second set of columns shows statistics for the Dollar Index adjusted index difference between the high and low levels for each tick. The third set of columns shows the difference between the raw and adjusted spreads. The t-test for mean differences compares the Dollar Index adjusted and raw index spreads. The F-test examines the variance differences of the two spreads. Finally, the last column reports the absolute value of the spread difference. ${ }^{* * *}$ indicates significance at the one percent level.

We use these calculations to assess distribution symmetry. To the extent that differences between the open and low equal differences between the close and low the intra tick distribution displays symmetry around the low level. Similar computations can be made for the Intra Tick high. Table 4 shows the results. The adjusted index spreads are narrower than the raw index spreads for each index and each spread measure. The spreads generally show symmetry between open-high differences and open-low differences. But, there exist some departures from symmetry. We use the Dow Jones Industrial Average, raw index, results to demonstrate. The open and high index level spread equals 3.871. The close and high index levels spread equals 3.790. For the Open-High raw spread, the minimum value equals -326.16 . For the Close-High spread the minimum value equals -241.68. Given the large number of observations examined in this study, these finding suggest considerable departure from symmetry.

Next, we explore the explanatory power of adjusted index components. We begin by examining index levels. This analysis involves three ordinary least squares regression analysis. We use regression analysis to determine the amount of variation in the adjusted index explained by the Dollar Index and the unadjusted index. The first regression determines the proportion of variation in adjusted index levels attributable to the raw stock index. The second regression determines the proportion of variation in adjusted index levels attributable to variation in the Dollar Index. The third regression determines the proportion of adjusted index level variation explained by the combined effects of raw index and Dollar Index changes. Equations 7, 8 and 9 show the specifications for each regression respectively.

$$
\begin{aligned}
& A I_{t}=\alpha+\beta_{1} R I_{t}+\varepsilon_{t} \\
& A I_{t}=\alpha+\beta_{1} D I_{t}+\varepsilon_{t} \\
& A I_{t}=\alpha+\beta_{1} R I_{t}+\beta_{2} D I_{t}+\varepsilon_{t}
\end{aligned}
$$


Table 4: Intra Tick Variance Analysis

\begin{tabular}{|c|c|c|c|c|c|c|c|c|c|}
\hline & \multirow[b]{2}{*}{$\mathbf{N}$} & \multicolumn{4}{|c|}{ Raw } & \multicolumn{4}{|c|}{ Adjusted } \\
\hline & & Mean & Std. Dev & Min & Max & Mean & Std. Dev & Min & Max \\
\hline \multicolumn{10}{|c|}{ Panel A: Dow Jones Industrial Average } \\
\hline Open - High & $1,035,860$ & -2.307 & 3.871 & -326.16 & 0 & -1.949 & 3.225 & -264.71 & 0 \\
\hline Open - Low & $1,035,860$ & 2.293 & 3.884 & 0.00 & 244.52 & 1.937 & 3.234 & 0 & 187.40 \\
\hline Close - High & $1,035,860$ & -2.301 & 3.790 & -241.68 & 0 & -1.944 & 3.160 & -185.22 & 0 \\
\hline Close - Low & $1,035,860$ & 2.299 & 3.769 & 0.00 & 319.39 & 1.942 & 3.144 & 0 & 259.22 \\
\hline \multicolumn{10}{|c|}{ Panel B: NASDAQ Composite } \\
\hline Open - High & $1,035,983$ & -0.3609 & 0.5952 & -79.44 & 0.00 & -0.3041 & 0.4963 & -62.21 & 0.00 \\
\hline Open - Low & $1,035,983$ & 0.3607 & 0.5986 & 0.00 & 38.96 & 0.3040 & 0.4988 & 0.00 & 30.24 \\
\hline Close - High & $1,035,983$ & -0.3608 & 0.5875 & -38.96 & 0.00 & -0.3041 & 0.4900 & -30.24 & 0.00 \\
\hline Close - Low & $1,035,983$ & 0.3609 & 0.5877 & 0.00 & 79.44 & 0.3040 & 0.4903 & 0.00 & 62.21 \\
\hline \multicolumn{10}{|c|}{ Panel C: NASDAQ 100 } \\
\hline Open - High & $1,036,067$ & -0.3866 & 0.6076 & -32.60 & 0.00 & -0.3266 & 0.5132 & -27.76 & 0.00 \\
\hline Open - Low & $1,036,067$ & 0.3869 & 0.6168 & 0.00 & 41.38 & 0.3268 & 0.5199 & 0.00 & 35.19 \\
\hline Close - High & $1,036,067$ & -0.3867 & 0.6016 & -37.90 & 0.00 & -0.3268 & 0.5080 & -32.23 & 0.00 \\
\hline Close - Low & $1,036,067$ & 0.3868 & 0.5978 & 0.00 & 32.35 & 0.3267 & 0.5054 & 0.00 & 27.54 \\
\hline \multicolumn{10}{|c|}{ Panel D: S\&P 500 } \\
\hline Open - High & $1,035,042$ & -0.1721 & 0.3324 & -0.1781 & 0.00 & -0.1447 & 0.2749 & -14.04 & 0.00 \\
\hline Open - Low & $1,035,042$ & 0.1715 & 0.3341 & 0.00 & 24.58 & 0.1442 & 0.2764 & 0.00 & 19.08 \\
\hline Close - High & $1,035,042$ & -0.1719 & 0.3310 & -24.58 & 0.00 & -0.1445 & 0.2740 & -19.08 & 0.00 \\
\hline Close - Low & $1,035,042$ & 0.1788 & 0.3284 & 0.00 & 17.81 & 0.1445 & 0.2718 & 0.00 & 14.04 \\
\hline \multicolumn{10}{|c|}{ Panel E: S\&P 400 } \\
\hline Open - High & $1,032,668$ & -0.0831 & 0.1900 & -10.06 & 0.00 & -0.0685 & 0.1533 & -9.298 & 0.00 \\
\hline Open - Low & $1,032,668$ & 0.0825 & 0.1924 & 0.00 & 13.26 & 0.06799 & 0.1553 & 0.00 & 11.31 \\
\hline Close - High & $1,032,668$ & -0.0825 & 0.1913 & -12.02 & 0.00 & -0.0680 & 0.01544 & -10.25 & 0.00 \\
\hline Close - Low & $1,032,668$ & 0.08311 & 0.1896 & 0.00 & 10.06 & 0.06844 & 0.1530 & 0.00 & 8.298 \\
\hline \multicolumn{10}{|c|}{ Panel F: Philadelphia Housing } \\
\hline Open - High & 985,347 & -0.0438 & 0.0740 & -4.490 & 0.00 & -0.0362 & 0.0605 & -3.548 & 0.00 \\
\hline Open - Low & 985,347 & 0.0438 & 0.0720 & 0.00 & 2.360 & 0.0362 & 0.0589 & 0.00 & 1.900 \\
\hline Close - High & 985,347 & -0.0439 & 0.0714 & -2.360 & 0.00 & -0.0362 & 0.0584 & -1.923 & 0.00 \\
\hline Close - Low & 985,347 & 0.0438 & 0.0729 & 0.00 & 4.450 & 0.0361 & 0.0596 & 0.00 & 3.548 \\
\hline \multicolumn{10}{|c|}{ Panel G: Russell 3000 } \\
\hline Open - High & $1,034,837$ & -0.0916 & 0.1750 & -15.45 & 0.00 & -0.0767 & 0.1440 & -12.54 & 0.00 \\
\hline Open - Low & $1,034,837$ & 0.0914 & 0.1756 & 0.00 & 9.99 & 0.0766 & 0.1446 & 0.00 & 7.649 \\
\hline Close - High & $1,034,837$ & -0.0916 & 0.1740 & -9.99 & 0.00 & -0.0767 & 0.1434 & -7.649 & 0.00 \\
\hline Close - Low & $1,034,837$ & 0.0915 & 0.1734 & 0.00 & 15.45 & 0.0766 & 0.1427 & 0.00 & 12.54 \\
\hline \multicolumn{10}{|c|}{ Panel H: Russell 1000 RUI } \\
\hline Open - High & $1,034,440$ & -0.0899 & 0.1689 & -14.82 & 0.00 & -0.0754 & 0.1394 & -12.03 & 0.00 \\
\hline Open - Low & $1,034,440$ & 0.08960 & 0.1695 & 0.00 & 9.45 & 0.7519 & 0.1399 & 0.00 & 7.236 \\
\hline Close - High & $1,034,440$ & -0.0897 & 0.1677 & -9.45 & 0.00 & -0.0753 & 0.1386 & -7.236 & 0.00 \\
\hline Close - Low & $1,034,440$ & 0.08975 & 0.1673 & 0.00 & 14.82 & 0.0753 & 0.1382 & 0.00 & 12.03 \\
\hline
\end{tabular}

Table 5 shows the regression results. The results show the independent variables significantly explain the dependent variable for each regression. This finding is not surprising given the methodology used to create the adjusted indices. The unadjusted stock index change and multiple regression analysis produces positive independent variable coefficient in each regression. The Dollar Index change coefficients show mixed signs. Five Dollar Index regressions have positive coefficients and three negative coefficients. Of primary interest is the R2 value for each regression. For the unadjusted stock index regression, the R2 varies from 0.4952 for the Dow Jones Industrial Average to 0.9621 for the Philadelphia Housing Index. This finding indicates unadjusted index levels explain as little as 49.52 percent of adjusted index levels. The dollar index change reveals R2 statistics ranging from 0.0062 to 0.1532. The findings indicate Dollar Index levels explain as much as 15.32 percent of adjusted index levels. The multiple regressions produce $\mathrm{R} 2$ statistics of 0.9872 and above. 
Table 5: Regression Analysis on Dollar Index Adjusted Return Indices Levels

\begin{tabular}{|c|c|c|c|c|c|c|c|}
\hline Dependent Variable & Intercept & $\begin{array}{c}\text { Unadjusted Stock } \\
\text { Index Levels }\end{array}$ & T-statistic & Intercept & $\begin{array}{c}\begin{array}{c}\text { Dollar Index } \\
\text { Levels }\end{array} \\
\end{array}$ & T-statistic & $\mathbf{R 2}$ \\
\hline \multicolumn{8}{|c|}{ Panel A: Single Regression for Unadjusted Stock Index Levels } \\
\hline Dow Jones Industrial & $3,732.99$ & 0.5055 & $1,008 * * *$ & & & & 0.4952 \\
\hline NASDA Composite & 562.46 & 0.5879 & $1,999 * * *$ & & & & 0.7942 \\
\hline NASDAQ 100 & 350.22 & 0.6403 & $2,757 * * *$ & & & & 0.8800 \\
\hline S\&P 500 & 343.69 & 0.5587 & $1,130 * * *$ & & & & 0.5521 \\
\hline S\&P 400 & 167.90 & 0.6075 & $2,628 * * *$ & & & & 0.8700 \\
\hline Philadelphia Housing & -0.6701 & 0.8902 & $5,001 * * *$ & & & & 0.9621 \\
\hline Russell 3000 & 200.89 & 0.5549 & $1,284 * * *$ & & & & 0.6142 \\
\hline Russell 1000 & 189.24 & 0.5542 & $1,232 * * *$ & & & & 0.5948 \\
\hline \multicolumn{8}{|c|}{ Panel B: Single Regression for Dollar Index Levels` } \\
\hline Dow Jones Industrial & & & & 7,135 & 24.870 & $218.5 * * *$ & 0.0440 \\
\hline NASDAQ & & & & 2,527 & -7.692 & $-255.9 * * *$ & 0.0595 \\
\hline \multicolumn{8}{|l|}{ Composite } \\
\hline NASDAQ 100 & & & & 2,400 & -10.706 & $-354.7 * * *$ & 0.1083 \\
\hline S\&P 500 & & & & 758.3 & 2.939 & $214.1 * * *$ & 0.0424 \\
\hline $\mathrm{S} \& \mathrm{P} 400$ & & & & 999.0 & -4.539 & $-432.3 * * *$ & 0.1532 \\
\hline Philadelphia Housing & & & & -70.37 & 2.368 & $387.9 * * *$ & 0.1325 \\
\hline Russell 3000 & & & & 528.2 & 0.6574 & $80.1^{* * *}$ & 0.0062 \\
\hline Russell 1000 & & & & 471.0 & 0.9093 & $119.5 * * *$ & 0.0135 \\
\hline \multicolumn{8}{|c|}{ Panel C: Multiple Regression } \\
\hline Dow Jones Industrial & $-8,326.37$ & 0.8318 & $10,261^{* * *}$ & & 99.28 & $7,424 * * *$ & 0.9907 \\
\hline NASDAQ & $-1,544.18$ & 0.8349 & $8,666^{* * * *}$ & & 18.21 & $3,953 * * *$ & 0.9872 \\
\hline \multicolumn{8}{|l|}{ Composite } \\
\hline NASDAQ 100 & $-1,159.60$ & 0.8227 & $9,811 * * *$ & & 13.87 & $3,471 * * *$ & 0.9905 \\
\hline S\&P 500 & -926.56 & 10.887 & $6,849 * * *$ & & 0.8424 & $10,074 * * *$ & 0.9903 \\
\hline S\&P 400 & -459.14 & 0.8207 & $8,887 * * *$ & & 5.516 & $3,355 * * *$ & 0.9891 \\
\hline Philadelphia Housing & -106.90 & 0.8585 & $19,366^{* * *}$ & & 1.249 & $3,930 * * *$ & 0.9977 \\
\hline Russell 3000 & -523.15 & 0.8417 & $9,829 * * *$ & & 6.148 & $6,072 * * *$ & 0.9895 \\
\hline Russell 1000 & -494.79 & 5.820 & $6,312 * * *$ & & 0.8415 & $9,924 * * *$ & 0.9897 \\
\hline \multicolumn{8}{|c|}{$\begin{array}{l}\text { This table shows regression results for Equations } 7,8 \text { and } 9 \text { which related to index levels. Panel A reports estimation results for } \\
\text { Equation } 7 \text {, specified: } \mathrm{AI}_{\mathrm{t}}=\alpha+\beta_{1} \mathrm{RI}_{\mathrm{t}}+\varepsilon_{\mathrm{t}} \text {. AI indicates the dollar adjusted stock index. RI indicates the original index. Panel B } \\
\text { reports estimation results for Equation } 8 \text {, specified: } \mathrm{AI}_{\mathrm{t}}=\alpha+\beta_{1} \mathrm{DI}_{\mathrm{t}}+\varepsilon_{\mathrm{t}} \text {. DI indicates the Dollar Index. Panel } \mathrm{C} \text { reports estimation } \\
\text { results for Equation } 9 \text {, specified: } \mathrm{AI}_{t}=\alpha+\beta_{1} \mathrm{RI}_{t}+\beta_{2} \mathrm{DI}_{t}+\varepsilon_{\mathrm{t}} \text {. } * * * \text { indicates significance at the } 1 \text { percent level. }\end{array}$} \\
\hline
\end{tabular}

To further examine the relationship between raw index levels and adjusted index levels, we examine how changes in raw index levels relate adjusted index changes. To complete the analysis we estimate the regressions depicted in equations 10-12.

$$
\begin{aligned}
& A I_{t}-A I_{t-1}=\alpha+\beta_{1}\left(R I_{t}-R I_{t-1}\right)+\varepsilon_{t} \\
& A I_{t}-A I_{t}=\alpha+\beta_{1}\left(D I_{t}-D I_{t-1}\right)+\varepsilon_{t} \\
& A I_{t}-A I_{t-1}=\alpha+\beta_{1}\left(R I_{t}-R I_{t-1}\right)+\beta_{2}\left(D I_{t}-D I_{t-1}\right)+\varepsilon_{t}
\end{aligned}
$$

The results presented in Table 6 correspond to those presented in Table 5. Similar to the results in Table 5, in each regression the coefficients are significant. Panel A shows R2 statistics for unadjusted stock index changes range from 0.6893 to 0.9339 . Panel B shows R2 statistics for the dollar index change range from 0.0144 to 0.1541 . Panel C shows multiple regression results. The multiple regression R2 statistics range from 0.9729 to 0.9853 .

Next, we examine Dollar Index adjusted index returns. To complete the analysis we estimate the regressions depicted in equations 13-14.

$$
\begin{aligned}
& \ln \left(\frac{A I_{t}}{A I_{t-1}}\right)=\alpha+\beta_{1} \ln \left(\frac{R I_{t}}{R I_{t-1}}\right)+\varepsilon_{t} \\
& \ln \left(\frac{A I_{t}}{A I_{t-1}}\right)=\alpha+\beta_{1} \ln \left(\frac{D I_{t}}{D I_{t-1}}\right)+\varepsilon_{t}
\end{aligned}
$$$$
\text { Copyright by author(s); CC-BY }
$$ 
Table 6: Regression Analysis on Dollar Index Adjusted Indices Changes

\begin{tabular}{|c|c|c|c|c|c|c|c|}
\hline $\begin{array}{l}\text { Dependent } \\
\text { Variable }\end{array}$ & Intercept & $\begin{array}{l}\text { Unadjusted Stock } \\
\text { Index Change }\end{array}$ & T-statistic & Intercept & $\begin{array}{c}\text { Dollar Index } \\
\text { Change }\end{array}$ & T-statistic & $\mathbf{R 2}$ \\
\hline \multicolumn{8}{|c|}{ Panel A: Single Regression for Unadjusted Stock Index Change } \\
\hline Dow Jones & -0.00319 & 0.7734 & $1,696 * * *$ & & & & 0.7353 \\
\hline \multicolumn{8}{|l|}{ Industrial } \\
\hline NASDAQ & -0.00057 & 0.7621 & $1,873 * * *$ & & & & 0.7719 \\
\hline \multicolumn{8}{|l|}{ Composite } \\
\hline NASDAQ 100 & -0.00048 & 0.7883 & $2,216 * * *$ & & & & 0.8258 \\
\hline S\&P 500 & -0.00036 & 0.7684 & $1,662 * * *$ & & & & 0.7273 \\
\hline $\mathrm{S} \& \mathrm{P} 400$ & -0.00011 & 0.7211 & $1,514 * * *$ & & & & 0.6893 \\
\hline Philadelphia & -0.00003 & 0.8207 & $3,731 * * *$ & & & & 0.9339 \\
\hline \multicolumn{8}{|l|}{ Housing } \\
\hline Russell 3000 & -0.00019 & 0.7506 & $1,568 * * *$ & & & & 0.7037 \\
\hline Russell 1000 & -0.00019 & 0.7573 & $1,600 * * *$ & & & & 0.7123 \\
\hline \multicolumn{8}{|c|}{ Panel B: Single Regression for Dollar Index Change } \\
\hline \multirow{2}{*}{\multicolumn{8}{|c|}{$\begin{array}{l}\text { Dow Jones } \\
\text { Industrial }\end{array}$}} \\
\hline & & & & & & & \\
\hline \multicolumn{8}{|l|}{ NASDAQ } \\
\hline \multicolumn{8}{|l|}{ Composite } \\
\hline NASDAQ 100 & & & & 0.00081 & 11,445 & $276.7 * * *$ & 0.0688 \\
\hline S\&P 500 & & & & 0.00022 & 8.4687 & $417.4 * * *$ & 0.1441 \\
\hline S\&P 400 & & & & 0.00048 & 4.8099 & $473.7 * * *$ & 0.1541 \\
\hline Philadelphia & & & & 0.00002 & 0.7593 & $120.2 * * *$ & 0.0144 \\
\hline \multicolumn{8}{|l|}{ Housing } \\
\hline Russell 3000 & & & & 0.00018 & 4.7863 & $431.1 * * *$ & 0.1522 \\
\hline Russell 1000 & & & & 0.00015 & 4.5317 & $425.8 * * *$ & 0.1491 \\
\hline \multicolumn{8}{|c|}{ Panel C: Multiple Regression } \\
\hline Dow Jones & 0.00012 & 0.8363 & $7,365 * * *$ & & 105.39 & $3,999 * * *$ & 0.9839 \\
\hline \multicolumn{8}{|l|}{ Industrial } \\
\hline NASDAQ & 0.00005 & 0.8238 & $6,326 * * *$ & & 21.126 & $3,055^{* * *}$ & 0.9772 \\
\hline \multicolumn{8}{|l|}{ Composite } \\
\hline NASDAQ 100 & 0.00003 & 0.8318 & $5,876 * * *$ & & 16.872 & $2,370 * * *$ & 0.9729 \\
\hline S\&P 500 & -0.00006 & 0.8339 & $7,229 * * *$ & & 11.405 & $3,993 * * *$ & 0.9834 \\
\hline $\mathrm{S} \& \mathrm{P} 400$ & 0.00007 & 0.7976 & $5,858 * * *$ & & 6.6406 & $3,457 * * *$ & 0.9753 \\
\hline Philadelphia & 0.00001 & 0.8418 & $8,073 * * *$ & & 1.441 & $1,858 * * *$ & 0.9853 \\
\hline \multicolumn{8}{|l|}{ Housing } \\
\hline Russell 3000 & 0.000007 & 0.8255 & $6,999 * * *$ & & 6.5577 & $4,056 * * *$ & 0.9825 \\
\hline Russell 1000 & 0.000003 & 0.8287 & $7,054 * * *$ & & 6.1731 & $4,017 * * *$ & 0.9827 \\
\hline \multicolumn{8}{|c|}{ 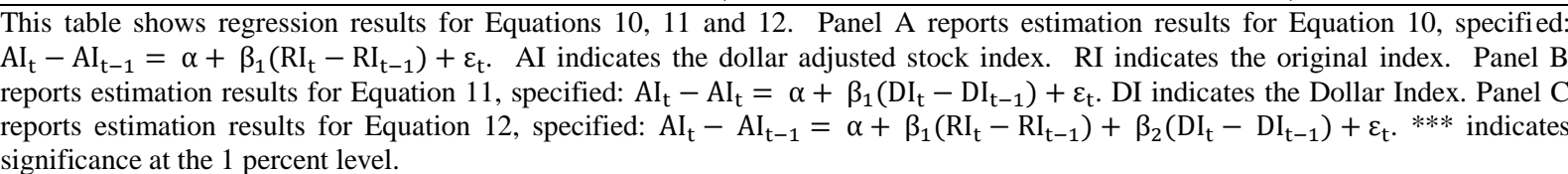 } \\
\hline
\end{tabular}

Table 7 shows the results. Again, the results show significant regression coefficients for each regression. Panel A shows R2 statistics for the unadjusted stock index returns range between 0.7262 and 0.9561 . Panel B shows R2 statistics for the Dollar Index change range from 0.0023 to 0.1439 . We do not present multiple regression results because the combined unadjusted stock index return and dollar index return create a linear combination and thus are not suitable for regression analysis.

Combined, the results show the Dollar Index explains between 0.23 and 15.41 percent of adjusted index levels, changes and returns. The unadjusted index explains between 49.52 percent and 96.21 percent of adjusted levels, changes and returns. For each regression, the coefficients are significant at the one percent level. The results here are consistent with the results of Jalbert (2014) who also used Dollar Index data, but who analyzed only closeof-day data. 


\section{CONCLUDING COMMENTS}

This paper examines new stock indexes which incorporate both traditional stock indexes and changes in the underlying currency value. This paper extends the extant literature by examining intraday data spanning the time period 2002-2013. Previous studies examine only daily closing data. This study provides a more detailed analysis of the impact of currency value adjusting indexes.

The results show negative correlation between the adjusted stock index and Dollar Index. Moreover, currency adjusted indices display lower volatility than raw indexes. Combined, these results suggest that raw indexes overestimate the volatility of wealth changes. The results show intra tick deviations from symmetry about the intra tick high and low values. Finally, results show that Dollar Index levels explain as much as 15.32 percent of wealth levels when the intercept is included in the regression. The results further show that Dollar Index changes explain as much as 15.41 percent of wealth changes.

The combined results clearly indicate the importance and value of currency adjusted indices. Individuals can gain added insights into the relative performance of their investments by examining currency adjusted indices. Asset pricing models based on unadjusted stock indexes overestimate market risk. Asset pricing models that have found little empirical support might produce better results when examined using currency adjusted indices.

There exists significant opportunity for research in this area. This study is limited to raw index levels which do not take into account dividends. Future work might examine dividend adjusted index levels to gain additional insights. This study is also limited to U.S. based indexes. However, stock indexes exist in many other countries. Future work might currency adjust indexes from other countries.

Table 7: Regression Analysis on Dollar Index Adjusted Returns

\begin{tabular}{|c|c|c|c|c|c|c|c|}
\hline $\begin{array}{l}\text { Dependent } \\
\text { Variable }\end{array}$ & Intercept & $\begin{array}{l}\text { Unadjusted Stock } \\
\text { Index Returns }\end{array}$ & T-statistic & Intercept & $\begin{array}{c}\text { Dollar Index } \\
\text { Returns }\end{array}$ & T-statistic & $\mathbf{R 2}$ \\
\hline \multicolumn{8}{|c|}{ Panel A: Single Regression for Unadjusted Stock Index Returns } \\
\hline $\begin{array}{l}\text { Dow Jones } \\
\text { Industrial }\end{array}$ & $<0.00001$ & 0.9237 & $1,884 * * *$ & & & & 0.7740 \\
\hline $\begin{array}{l}\text { NASDAQ } \\
\text { Composite }\end{array}$ & $<0.00001$ & 0.9352 & $2,155 * * *$ & & & & 0.8176 \\
\hline NASDAQ 100 & $<0.00001$ & 0.9631 & $2,702 * * *$ & & & & 0.8757 \\
\hline S\&P 500 & $<0.00001$ & 0.9189 & $1,859 * * *$ & & & & 0.7696 \\
\hline S\&P 400 & $<0.00001$ & 0.9090 & $1,653 * * *$ & & & & 0.7262 \\
\hline $\begin{array}{l}\text { Philadelphia } \\
\text { Housing }\end{array}$ & $<0.00001$ & 0.9659 & $4,634 * * *$ & & & & 0.9561 \\
\hline Russell 3000 & $<0.00001$ & 0.9087 & $1,751 * * *$ & & & & 0.7476 \\
\hline Russell 1000 & $<0.00001$ & 0.9128 & $1,792 * * *$ & & & & 0.7564 \\
\hline \multicolumn{8}{|c|}{ Panel B: Single Regression for Dollar Index Returns } \\
\hline $\begin{array}{l}\text { Dow Jones } \\
\text { Industrial }\end{array}$ & & & & $<0.00001$ & 0.7005 & $364.17 * * *$ & 0.1135 \\
\hline $\begin{array}{l}\text { NASDAQ } \\
\text { Composite }\end{array}$ & & & & $<0.00001$ & 0.6746 & $309.81 * * *$ & 0.0848 \\
\hline NASDAQ 100 & & & & $<0.00001$ & 0.7227 & $269.67 * * *$ & 0.0656 \\
\hline S\&P 500 & & & & $<0.00001$ & 0.6873 & $360.70 * * *$ & 0.1117 \\
\hline S\&P 400 & & & & $<0.00001$ & 0.7155 & $416.63 * * *$ & 0.1439 \\
\hline $\begin{array}{l}\text { Philadelphia } \\
\text { Housing }\end{array}$ & & & & $<0.00001$ & 0.2235 & $47.16^{* * *}$ & 0.0023 \\
\hline Russell 3000 & & & & $<0.00001$ & 0.6820 & $377.24 * * *$ & 0.1209 \\
\hline Russell 1000 & & & & $<0.00001$ & 0.6840 & $370.54 * * *$ & 0.1172 \\
\hline \multicolumn{8}{|c|}{$\begin{array}{l}\text { This table shows regression results for Equations } 13 \text { and } 14 \text {. Panel } \mathrm{A} \text { reports estimation results for Equation 13, specified: } \\
\ln \left(\frac{\mathrm{AI}_{\mathrm{t}}}{\mathrm{AI}_{\mathrm{t}-1}}\right)=\alpha+\beta_{1} \ln \left(\frac{\mathrm{RI}_{\mathrm{t}}}{\mathrm{RI}_{\mathrm{t}-1}}\right)+\varepsilon_{\mathrm{t}} \text {. AI indicates the dollar adjusted stock index. RI indicates the original index. Panel B reports } \\
\text { estimation results for Equation 14, specified: } \ln \left(\frac{\mathrm{AI}_{\mathrm{t}}}{\mathrm{AI}_{\mathrm{t}-1}}\right)=\alpha+\beta_{1} \ln \left(\frac{\mathrm{DI}_{\mathrm{t}}}{\mathrm{DI}_{\mathrm{t}-1}}\right)+\varepsilon_{\mathrm{t}} \text {. DI indicates the Dollar Index. *** indicates } \\
\text { significance at the } 1 \text { percent level. }\end{array}$} \\
\hline
\end{tabular}




\section{AUTHOR INFORMATION}

Terrance Jalbert, Ph.D. is Professor of Finance at University of Hawaii at Hilo. His research appears in journals including International Journal of Finance, Financial Services Review, Journal of Emerging Markets, The International Journal of Business and Finance Research and Journal of Index Investing. He can be reached at: jalbert@hawaii.edu

\section{REFERENCES}

1. Alvarez-Ramirez, J., and E. Rodriguez (2011) "Long-Term Recurrence Patterns in the Late 2000 Economic Crisis: Evidences from Entropy Analysis of the Dow Jones Index," Technological Forecasting and Social Change, v. 78(8), p. 1332-1344

2. Beneish, M. and J. Gardner (1995) "Information Costs and Liquidity Effects from changes in the Dow Jones Industrial Average list," Journal of Financial and Quantitative Analysis, vol. 30, p. 135-157

3. Black, F. and M. Scholes (1973) "The Pricing of Options and Corporate Liabilities," Journal of Political Economy, vol. 81 (May/June), p. 637-659

4. Bollerslev, T. R.F. Engle, J.M. Wooldridge (1988) "A Capital Asset Pricing Model with Time Varying

5. $\quad$ Covariances," Journal of Political Economy, vol. 96 p. 116-131

6. Breen, W., L.R. Glosten, and R. Jagannathan (1989) "Economic Significance of Predictable Variations in Stock Index Returns," The Journal of Finance, vol. XLIV (5, December), p. 1177-1189

7. Chen, H., G. Noronha and V. Singal (2006) "Index Changes and Losses to Index Fund Investors,"

8. $\quad$ Financial Analysts Journal, vol. 62(4) p. 31-47

9. Christie, A. A. (1982) "The Stochastic Behavior of Common Stock Variances: Value, Leverage and Interest Rate Effects," Journal of Financial Economics, vol. 10, p. 407-432

10. Donaldson, R.G. and H.Y. Kim (1993) "Price Barriers in the Dow Jones Industrial Average," Journal of Financial and Quantitative Analysis, vol. 28(3, September) p. 313-330

11. French and Roll (1986) "Stock Return Variances: The Arrival of Information and the Reaction of Traders," Journal of Financial Economics, vol. 17, p. 5-26

12. Ferreira, T.A.E., G.C. Vasconcelos, and P.J.L. Adeodato (2008) "A New Intelligent system methodology for Time Series Forecasting with Artificial Neural Networks," Neural Process Letters, vol. 28, p. 113-129

13. Hora, S., and T. Jalbert (2006) "The Dow Jones Industrial Average in the Twentieth Century - Implications for Option Pricing," Academy of Accounting and Financial Studies Journal, vol. 10(3) p. 17-40

14. Jalbert, T. (2012) "The Performance of Currency Value Adjusted Stock Indices," The Journal of Index Investing, vol. 3(2), p. 34-48

15. Jalbert, Terrance (2014) “Dollar Index Adjusted Stock Indices," Journal of Applied Business Research, vol. 30(1) p. $1-13$

16. Jankovskis, P. (2002) “The Impact of Russell 2000 Rebalancing on Small-Cap Performance,” The Journal of Investment Consulting, vol. 5(2) p. 23-29

17. Koch, C. (2013) "What is the DXY Index," Ezine Articles, November 22, downloaded 06/18/2013 from http://ezinearticles.com/?What-Is-the-DXY-Dollar-Index?\&id=5381416

18. Lakonishok J and S. Smidt (1988) "Are Seasonal Anomalies Real? A Ninety-Year Perspective," The Review of Financial Studies, vol. 1(4) p. 403-425

19. Lauterbach, B. (1989) "Consumption Volatility, Production Volatility, Spot Rate Volatility and the Returns on Treasury Bills and Bonds," Journal of Financial Economics vol. 24(1) p. 155-179

20. Liu, Shinhau (2011) "The Price Effects of Index Additions: A New Explanation," Journal of Economics and Business, vol. 63. p. 152-165

21. Martens, M., D. van Dijk and M. de Pooter (2009) "Forecasting S\&P 500 Volatility: Long Memory, Level Shifts, Leverage Effects, Day-of-the-week Seasonality and Macroeconomic Announcements," International Journal of Forecasting, vol. 25(2, April-June), p. 282-303

22. Merton, R.C. (1980) "On Estimating the Expected Return on the Market: An Exploratory Investigation, Journal of Financial Economics, vol. 8, p. 323-361

23. Opong, K. K. G. Mulholland, A.F. Fox and K Farahmand (1999) "The Behavior of some UK Equity Indexes: An Application of Hurst and BDS Tests," Journal of Empirical Finance, vol. 6, p. 267-282

24. Pitrading.com http://pitrading.com/ 
25. Shleifer, A. (1986) Do Demand Curves for Stocks Slope Down?,” Journal of Finance, vol. 41, p. 579-590

26. Taylor, N. (2007) Á New Econometric Model of Index Arbitrage," European Financial Management, vol. 13(1) p. 159-183

27. Wong, J.C. H. Lian and S.A. Cheong (2009) "Detecting Macroeconomic Phases in the Dow Jones Industrial Average Time Series," Physica A: Statistical Mechanics and its Applications, vol. 388 (21, November), p. 4635-4645 